\title{
Cell Cycle-Regulated Phosphorylation of the Pre-mRNA- Binding (Heterogeneous Nuclear Ribonucleoprotein) C Proteins
}

\author{
SERAFÍN PIÑOL-ROMA AND GIDEON DREYFUSS* \\ Howard Hughes Medical Institute and Department of Biochemistry and Biophysics, University of \\ Pennsylvania School of Medicine, Clinical Research Building, Room 328, 422 Curie Boulevard, \\ Philadelphia, Pennsylvania 19104-6148
}

Received 12 April 1993/Returned for modification 17 May 1993/Accepted 20 June 1993

\begin{abstract}
Heterogeneous nuclear ribonucleoprotein (hnRNP) complexes, the structures that contain heterogeneous nuclear RNA and its associated proteins, constitute one of the most abundant components of the eukaryotic nucleus. hnRNPs appear to play important roles in the processing, and possibly also in the transport, of mRNA. hnRNP C proteins $\left(C 1, M_{\mathrm{r}}\right.$ of 41,$000 ; \mathrm{C2}, M_{\mathrm{r}}$ of 43,000 [by sodium dodecyl sulfate-polyacrylamide gel electrophoresis]) are among the most abundant pre-mRNA-binding proteins, and they bind tenaciously to sequences relevant to pre-mRNA processing, including the polypyrimidine stretch of introns (when it is uridine rich). $\mathrm{C}$ proteins are found in the nucleus during the interphase, but during mitosis they disperse throughout the cell. They have been shown previously to be phosphorylated in vivo, and they can be phosphorylated in vitro by a casein kinase type II. We have identified and partially purified at least two additional $C$ protein kinases. One of these, termed $\mathrm{Cs}$ kinase, caused a distinct mobility shift of $\mathrm{C}$ proteins on sodium dodecyl sulfate-polyacrylamide gel electrophoresis. These phosphorylated $\mathbf{C}$ proteins, the $\mathbf{C s}$ proteins, were the prevalent forms of $\mathbf{C}$ proteins during mitosis, and Cs kinase activity was also increased in extracts prepared from mitotic cells. Thus, hnRNP C proteins undergo cell cycle-dependent phosphorylation by a cell cycle-regulated protein kinase. Cs kinase activity appears to be distinct from the well-characterized mitosis-specific histone $\mathbf{H 1}$ kinase activity. Several additional hnRNP proteins are also phosphorylated during mitosis and are thus also potential substrates for Cs kinase. These novel phosphorylations may be important in regulating the assembly and disassembly of hnRNP complexes and in the function or cellular localization of RNA-binding proteins.
\end{abstract}

RNA polymerase II transcripts, collectively termed heterogeneous nuclear RNAs (hnRNAs), associate as they are transcribed in the nuclei of eukaryotic cells with a specific subset of proteins to form heterogeneous nuclear ribonucleoprotein (hnRNP) complexes $(12,15)$. In human HeLa cells, these complexes contain, in addition to hnRNA, an assortment of at least 20 different abundant polypeptides $(7,30)$. As this association persists throughout their nuclear residency, it is assumed that the ensuing events that pre-mRNAs undergo to become functional translatable cytoplasmic mRNAs occur on hnRNPs rather than on naked RNA molecules.

Of the ca. 20 major hnRNP proteins identified, the $\mathrm{C}$ proteins have occupied much of the focus of hnRNP research for several reasons. They are a prominent doublet $(\mathrm{Cl}$ [41 kDa] and C2 [43 kDa]) in HeLa cells) of nuclear acidic proteins which remain bound to the RNA at salt concentrations at which most of the other hnRNPs dissociate $(3,7)$. C proteins can also be readily UV-cross-linked to poly(A)containing nuclear RNA in vivo $(13,14,42)$. Immunofluorescence microscopy with monoclonal antibodies in a variety of vertebrate cells has shown that $\mathrm{C}$ proteins are localized to the nucleoplasm and are excluded from nucleoli and from the cytoplasm in interphase cells (8). C proteins are highly conserved among vertebrates, both immunologically $(8)$ and in their amino acid sequences $(25,35,39)$, suggesting an essential cellular function. Antibody inhibition and immunodepletion experiments in vitro implicated a role for $\mathrm{C}$

\footnotetext{
* Corresponding author.
}

proteins in pre-mRNA splicing (9). Consistent with both a possible role for $\mathrm{C}$ proteins in pre-mRNA processing and the preference they have for uridine-rich sequences (37), C proteins bind preferentially to RNA fragments derived from the $3^{\prime}$ end of introns, including the uridine-rich polypyrimidine stretch (38), as well as to such segments often found downstream of the 3 '-end cleavage and polyadenylation sites $(24,44)$.

$\mathrm{C} 2$ is identical to $\mathrm{C} 1$, except for a 13 -amino-acid insertion at about the middle of the protein in $\mathrm{C} 2$ that results from a 39-nucleotide insert in the corresponding mRNA. The nucleotide sequences of cDNAs for $\mathrm{C} 1$ and $\mathrm{C} 2$ are otherwise identical, suggesting that they are derived from a common pre-mRNA by alternative splicing (5). The amino acid sequences of $\mathrm{C}$ proteins indicate a two-domain structure: the amino-terminal half of the protein contains an RNP consensus sequence RNA-binding domain $(2,16,39)$, and the carboxy-terminal domain of the protein contains a highly acidic stretch of amino acids which include a putative nucleoside triphosphate-binding site and multiple potential casein kinase type II phosphorylation sites (39). This carboxy terminus may be important for interactions with other proteins, as well as for modulation of the interactions of $\mathrm{C}$ proteins with RNA and their subcellular localization $(2,39)$. The $\mathrm{C}$ proteins have been shown to be phosphorylated in vivo $(8,14,18,43)$, and a casein kinase type II activity (NKII) was found to phosphorylate them in vitro (18).

Here we describe novel phosphorylations of the $\mathrm{C}$ proteins in HeLa cells. In addition to the previously described phosphorylation of the C proteins by NKII, we found that at least two additional, distinct $\mathrm{C}$ protein kinase activities are 
present in HeLa cells. All three kinase activities can be readily separated chromatographically, and one of them causes a retardation in the electrophoretic mobility of $\mathrm{C}$ proteins on sodium dodecyl sulfate (SDS)-polyacrylamide gel electrophoresis (PAGE). Interestingly, such electrophoretically distinct forms of $\mathrm{C}$ proteins are most prevalent in cells in the mitotic phase of the cell cycle, during which there is a dramatic redistribution of hnRNPs and other nuclear components, as well as overall repression of transcription by RNA polymerase II and probably also of RNA processing events. The activity responsible for this conversion is also enriched in extracts prepared from mitotic cells, and it can be separated from histone H1 kinase activity. These results show that hnRNP $C$ proteins, and possibly several other hnRNP proteins, undergo mitosis-specific phosphorylation by a novel cell cycle-regulated kinase. The possible implications of this modification are discussed.

\section{MATERIALS AND METHODS}

Cell culture and synchronization. HeLa cells were cultured in monolayer at $37^{\circ} \mathrm{C}$ in Dulbecco's modified Eagle's medium containing penicillin, streptomycin, and $10 \%$ fetal calf serum. Where indicated, cells were partly synchronized by a single block with thymidine (Sigma) added to the culture medium to a final concentration of $2 \mathrm{mM}$ for $12 \mathrm{~h}$ (4). Also where indicated, methyl(5-[2-thienylcarbonyl]-1H-benzimidazol-2-yl)carbamate (nocodazole; Sigma) was added $4 \mathrm{~h}$ after removal of thymidine, to a final concentration of 5 $\mu \mathrm{g} / \mathrm{ml}$, and the cells were incubated for an additional 12 to 14 $\mathrm{h}$ to arrest and accumulate cells in mitosis (46). Mitotic HeLa cells were collected by selective mitotic detachment as previously described (41). For in vivo labeling, cells were incubated for $2.5 \mathrm{~h}$ at $37^{\circ} \mathrm{C}$ in Dulbecco's modified Eagle's medium containing $1 / 10$ of the normal concentration of phosphate, $10 \%$ fetal calf serum, and $150 \mu \mathrm{Ci}$ of ${ }^{32} \mathrm{P}_{i}$ per $\mathrm{ml}$.

Preparation and incubation of HeLa cell nuclear extracts. HeLa cell nuclear extracts were prepared essentially as described by Dignam et al. (11). Reaction mixtures contained $20 \mathrm{mM} N$-2-hydroxyethylpiperazine- $N$ '-2-ethanesulfonic acid (HEPES; pH 7.6), $2 \mathrm{mM} \mathrm{MgCl}$, $1.5 \mathrm{mM}$ ATP, $5 \mathrm{mM}$ creatine phosphate, and HeLa cell nuclear extract $(40 \%, \mathrm{vol} / \mathrm{vol})$ in a final reaction volume of $25 \mu \mathrm{l}$. Reactions were initiated by addition of nuclear extract and allowed to proceed at $30^{\circ} \mathrm{C}$ for $30 \mathrm{~min}$. ATP and creatine phosphate were omitted in control reactions without ATP. Reactions were stopped by addition of an equal volume of $2 \times$ SDSPAGE sample buffer (13) for direct analysis by SDS-PAGE and immunoblotting or by addition of ice-cold Empigen BB-containing buffer (8) for immunopurification analysis (see below). Where indicated, [ $\gamma$-thio]ATP (Boehringer Mannheim Biochemicals) was substituted for ATP.

Antibody preparation and immunopurification analysis. Monoclonal antibody 4F4 against the $\mathrm{C}$ proteins was prepared in the form of ascites fluid as previously described (8). Immunopurification of $C$ proteins was carried out in the presence of the ionic detergent Empigen BB at $1 \%$ in phosphate-buffered saline (PBS), containing $1 \mathrm{mM}$ EDTA, $0.1 \mathrm{mM}$ dithiothreitol (8), and $10 \mathrm{mM} \mathrm{NaF}$. Immunopurification of hnRNP complexes from ${ }^{32} \mathrm{P}$-labeled asynchronous and mitotic $\mathrm{HeLa}$ cells was carried out with $4 \mathrm{~F} 4$ as previously described $(7,30,31)$.

Phosphatase treatment. Digestions with calf intestine alkaline phosphatase (CIP; Boehringer Mannheim Biochemicals) were carried out at $37^{\circ} \mathrm{C}$ for $2 \mathrm{~h}$ in a reaction volume of $25 \mu \mathrm{l}$ containing $50 \mathrm{mM}$ Tris- $\mathrm{HCl}(\mathrm{pH} 8.0)$ and $2 \mathrm{U}$ of CIP.
Reactions were stopped by addition of SDS-PAGE sample buffer.

Fractionation of nuclear extracts. Nuclear extract from HeLa cells was adjusted to $10 \%$ glycerol-50 mM KCl, clarified by a brief $(5-\mathrm{min})$ centrifugation at $13,000 \times \mathrm{g}$, and loaded onto a Hydropore-300A AX anion-exchange highpressure liquid chromatography column $(4.5 \mathrm{~mm}$ [inside diameter] by $10 \mathrm{~cm}$ [length]; Rainin Instruments). Elution was performed with a linear gradient of 50 to $500 \mathrm{mM} \mathrm{KCl}$ in buffer F (20 mM HEPES [pH 7.6], 10\% glycerol, $0.2 \mathrm{mM}$ EDTA, $1.5 \mathrm{mM} \mathrm{MgCl} 2,0.5 \mathrm{mM}$ dithiothreitol), developed over $30 \mathrm{~min}$ at a flow rate of $1 \mathrm{ml} / \mathrm{min}$. Fractions of $1 \mathrm{ml}$ each were collected and stored at $-70^{\circ} \mathrm{C}$ until further analysis. Cation-exchange chromatography was carried out with an SP-5PW column $(7.5 \mathrm{~mm}$ [inside diameter] by $7.5 \mathrm{~cm}$ [length]; Waters) under the same run conditions.

Gel filtration chromatography. Mitotic JW36 cells $(1.5 \times$ $10^{7}$ ) obtained by selective mitotic detachment from nocodazole-treated culture monolayers as described above were washed in PBS and resuspended in $10 \mathrm{mM}$ Tris- $\mathrm{HCl}(\mathrm{pH}$ 7.4)-100 mM NaCl-2.5 mM MgCl $2-0.2 \%$ Triton X-100-0.5\% aprotinin-1 $\mu \mathrm{g}$ each of leupeptin and pepstatin A per ml-10 $\mathrm{mM} \mathrm{NaF}$. The cells were sonicated three times for $5 \mathrm{~s}$ each time with a microtip sonicator (w-220F; Heat Systems/ Ultrasonics, Plainview, N.Y.) set at scale 2.5 , on ice. The sonicated material was ciarified by centrifugation at $13,000 \times$ $g$ for $10 \mathrm{~min}$ at $4^{\circ} \mathrm{C}$ and loaded on a $2-\mathrm{ml} \mathrm{S}$-Sepharose column (Sigma) equilibrated in buffer $\mathrm{F}$ containing $50 \mathrm{mM} \mathrm{KCl}$. Bound proteins were eluted with a linear 50 to $500 \mathrm{mM} \mathrm{KCl}$ gradient over $30 \mathrm{~min}$ at a flow rate of $0.5 \mathrm{ml} / \mathrm{min}$. Fractions $(0.5 \mathrm{ml})$ were collected and assayed for Cs kinase activity. Peak fractions were pooled, concentrated to $0.5 \mathrm{ml}$ by centrifugation with a Centricon filter (Amicon), and fractionated on a Superose 12 gel filtration column (Pharmacia) in buffer $\mathrm{F}$ containing $50 \mathrm{mM} \mathrm{KCl}$, at a flow rate of $0.2 \mathrm{ml} / \mathrm{min}$. Fractions $(0.25 \mathrm{ml})$ were collected and assayed for $\mathrm{Cs}$ and histone $\mathrm{H} 1$ kinase activities as described below.

Partial purification of hnRNP C proteins. $C$ proteins were partially purified from HeLa cell nucleoplasm by affinity chromatography on single-stranded DNA-agarose essentially as previously described (30). Briefly, nucleoplasm was digested with micrococcal nuclease and loaded on a singlestranded DNA-agarose column (Bethesda Research Laboratories) in $50 \mathrm{mM} \mathrm{Na}$ phosphate (pH 7.4) containing $100 \mathrm{mM}$ $\mathrm{NaCl}$, and the column was sequentially washed with $1 \mathrm{mg}$ of heparin per $\mathrm{ml}$ in $100 \mathrm{mM} \mathrm{NaCl}$ and with $0.7 \mathrm{M} \mathrm{NaCl}$. C proteins were eluted with $2.0 \mathrm{M} \mathrm{NaCl}$, and the peak fractions were pooled and dialyzed for $5 \mathrm{~h}$ against buffer $\mathrm{F}$ containing $50 \mathrm{mM} \mathrm{KCl}$. The identity of the $\mathrm{C}$ proteins was confirmed by two-dimensional gel electrophoresis and by immunoblotting with monoclonal antibody 4F4. The final preparation contained at least $60 \% \mathrm{C}$ proteins, as judged from Coomassie blue staining of SDS-PAGE gels, and was devoid of endogenous $C$ protein kinase activity (data not shown).

Protein kinase assays of column fractions. Aliquots (5 to 10 $\mu \mathrm{l})$ of the fractions to be assayed were incubated with $0.5 \mu \mathrm{g}$ of partially purified $\mathrm{C}$ proteins in a final reaction volume of $25 \mu \mathrm{l}$ containing $0.075 \mathrm{mM}\left[\gamma^{-32} \mathrm{P}\right] \mathrm{ATP}(10 \mu \mathrm{Ci}$ per reaction $)$, $20 \mathrm{mM}$ HEPES (pH 7.6), and $2 \mathrm{mM} \mathrm{MgCl}_{2}$ for $30 \mathrm{~min}$ at $30^{\circ} \mathrm{C}$. Reactions were stopped by addition of $500 \mu \mathrm{l}$ of ice-cold $1 \%$ Empigen BB in PBS containing $1 \mathrm{mM}$ EDTA, $0.1 \mathrm{mM}$ dithiothreitol (8), and $10 \mathrm{mM} \mathrm{NaF}$, and $\mathrm{C}$ proteins were immunopurified by incubation with 4F4-coated protein A-Sepharose beads at $4^{\circ} \mathrm{C}$ for $30 \mathrm{~min}$. After the beads were washed with immunopurification buffer, proteins were eluted by boiling in $50 \mu \mathrm{l}$ of SDS-PAGE sample buffer. For 
histone $\mathrm{H} 1$ kinase assays, identical reactions were performed except that $1 \mu \mathrm{g}$ of histone H1 (type III-S; Sigma) was substituted for $\mathrm{C}$ proteins and the cyclic AMP-dependent kinase inhibitor PKI (Sigma Chemical Co.) (6) was added to $0.5 \mu \mathrm{M}$. Reactions were stopped by addition of an equal volume of $2 \times$ SDS-PAGE sample buffer. Proteins were resolved by SDS-PAGE, and phosphorylation was determined by autoradiography. Where indicated, the following were included in the reaction at the final concentrations shown: heparin (Sigma), $10 \mu \mathrm{g} / \mathrm{ml}$; spermidine (Aldrich Biochemicals), $1 \mathrm{mM}$; DRB (5,6-dichloro-1- $\beta$-D-ribofuranosylbenzimidazole; Sigma), $75 \mu \mathrm{M}$. When $\left[\gamma-{ }^{32} \mathrm{P}\right] \mathrm{GTP}$ was used, its specific activity was adjusted to that of the $\left[\gamma-{ }^{32} \mathrm{P}\right] \mathrm{ATP}$ used in the typical assays. $\left[\gamma-{ }^{32} \mathrm{P}\right] \mathrm{ATP}$ and $\left[\gamma-{ }^{32} \mathrm{P}\right] \mathrm{GTP}$ were from ICN Biochemicals.

Phosphopeptide mapping of $\mathbf{C}$ proteins. Phosphorylated $\mathrm{C}$ proteins were isolated from cells labeled with ${ }^{32} \mathbf{P}_{i}$, or from in vitro Cs kinase reactions by immunopurification in Empigen BB-containing buffer. C proteins were resolved by SDSPAGE, and the gel was dried without fixing and exposed to $\mathrm{X}$-ray film to locate the radiolabeled $\mathrm{C}$ proteins. The regions of the gel corresponding to the $\mathrm{C} 1, \mathrm{C} 2, \mathrm{C} 1 \mathrm{~s}$, and $\mathrm{C} 2 \mathrm{~s}$ proteins were excised with a razor blade, hydrated with $\mathrm{H}_{2} \mathrm{O}$, and washed five times, for 15 min each time, with $10 \%$ methanol to remove SDS and Tris from the gel slices. The slices were then cut into small pieces and lyophilized, and each tube was incubated with $500 \mu$ l of $50 \mathrm{mM}$ ammonium bicarbonate $(\mathrm{pH}$ 8.1) containing $50 \mu \mathrm{g}$ of tolylsulfonyl phenylalanyl chloromethyl ketone (TPCK)-trypsin (Worthington). Digestion was allowed to proceed overnight at $37^{\circ} \mathrm{C}$, after which $25 \mu \mathrm{g}$ of fresh trypsin was added and digestion was continued for an additional $5 \mathrm{~h}$. At the end of the digestion, the reaction mixtures were freeze-dried and taken through four additional cycles of washes with decreasing volumes $(500,250,100$, and $50 \mu \mathrm{l}$, successively) of distilled $\mathrm{H}_{2} \mathrm{O}$ and lyophilization. The digested peptides were resuspended in $25 \mu \mathrm{l}$ of $\mathrm{pH} 1.9$ buffer (formic acid-acetic acid- $\mathrm{H}_{2} \mathrm{O}, 50: 156: 1,794$ ) and resolved by electrophoresis on Kodak thin-layer chromatography plates $(20$ by $20 \mathrm{~cm}$ ) in pH 1.9 buffer at $20 \mathrm{~mA}$ for $40 \mathrm{~min}$ in the first dimension, essentially as previously described (10), and by ascending chromatography in butanol-pyridineacetic acid- $\mathrm{H}_{2} \mathrm{O}(15: 10: 3: 12)$ in the second dimension. The plates were air dried and exposed to X-ray film.

UV light-induced cross-linking of proteins to RNA. HeLa cell nuclear extracts were preincubated for $20 \mathrm{~min}$ in the absence or presence of ATP, and a continuously labeled RNA transcript derived from the adenovirus type 2 major late transcription unit and transcribed with bacteriophage SP6 RNA polymerase in the presence of $\left[\alpha-{ }^{32}\right.$ P]UTP (see reference 9) was added to the extract. The extract was incubated for a further $10 \mathrm{~min}$ at $30^{\circ} \mathrm{C}$ to allow binding of proteins to the added RNA and then exposed to UV light for $10 \mathrm{~min}$ at $4^{\circ} \mathrm{C}$ as previously described (29). After exhaustive digestion with $400 \mathrm{U}$ of micrococcal nuclease and $25 \mu \mathrm{g}$ of RNase A per $\mathrm{ml}$, the $\mathrm{C}$ and Cs proteins were specifically immunopurified with monoclonal antibody 4F4 and resolved by SDS-PAGE, and covalent cross-linking to the RNA by label transfer from the RNA to C proteins was detected by autoradiography.

Gel electrophoresis and immunoblotting. SDS-PAGE of proteins and immunoblotting procedures were done as previously described (13). For two-dimensional gel analysis, proteins were separated by nonequilibrium $\mathrm{pH}$ gradient gel electrophoresis in the first dimension and by SDS-PAGE in the second dimension as previously described $(27,30)$.

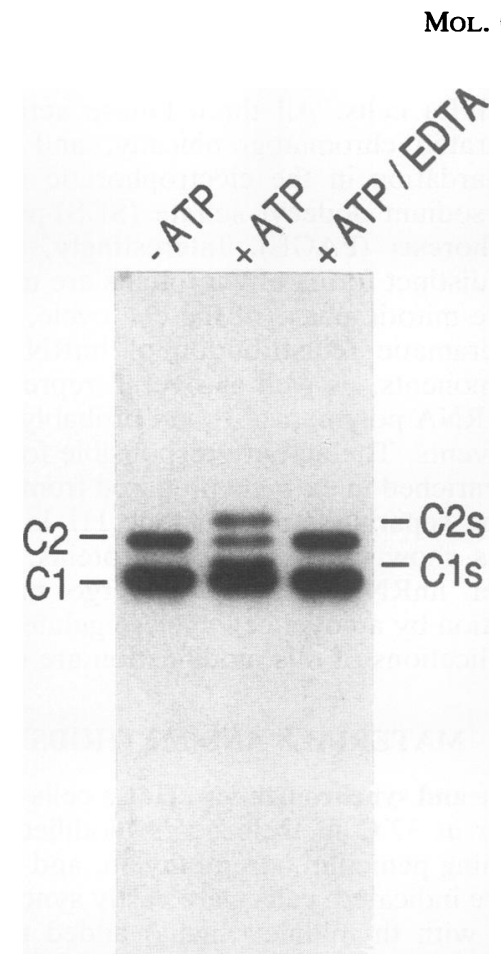

FIG. 1. ATP-dependent modification of the $\mathrm{C}$ proteins in nuclear extracts. HeLa cell nuclear extract was incubated in the absence (lane - ATP) or presence (lane + ATP) of ATP and creatine phosphate as described in the text. At the end of the reaction, the proteins were resolved by SDS-PAGE and the $C$ proteins were detected by immunoblotting with monoclonal antibody 4F4. Lane +ATP/EDTA, reaction identical to that in lane +ATP, except that it was carried out in the presence of $10 \mathrm{mM}$ EDTA.

\section{RESULTS}

hnRNP $C$ proteins are modified in nuclear extracts in the presence of ATP. In the course of experiments on the interaction of the hnRNP C proteins with pre-mRNA, we noticed that incubation of nuclear extracts with ATP under splicing conditions resulted in the appearance of novel, electrophoretically distinct forms of $\mathrm{C}$ proteins. These more slowly migrating forms, which we term Cs proteins, were readily detectable by immunoblotting with anti-C-protein monoclonal antibodies (Fig. 1, lane +ATP). The appearance of C1s and C2s is dependent on ATP, since they were not detected in nuclear extracts incubated under the same conditions but in the absence of exogenous ATP (lane -ATP). Similarly, no C1s or C2s was detectable when excess EDTA over $\mathrm{Mg}^{2+}$ was present (lane +ATP/EDTA). Identical results were observed regardless of whether exogenous RNA was added to or omitted from the reaction. Because of the reactivity of $\mathrm{C} 1 \mathrm{~s}$ and $\mathrm{C} 2 \mathrm{~s}$ with anti-C-protein monoclonal antibody $4 \mathrm{~F} 4$, as well as with a monoclonal antibody, $2 \mathrm{~B} 12$ (data not shown), that also recognizes $\mathrm{C}$ proteins but on a different epitope (8), it appears that the $C 1 s$ and $C 2$ s proteins result from covalent posttranslational modification of the $\mathrm{C} 1$ and $\mathrm{C} 2$ proteins.

C1s and C2s are sensitive to CIP. Cs proteins appeared to be more acidic than $\mathrm{C}$ proteins by two-dimensional gel electrophoresis, and they were labeled efficiently upon incubation with $\left[\gamma^{32}\right.$ P]ATP (see below), which suggests that the modification may result from phosphorylation by a protein kinase present in the nuclear extract. We therefore tested whether Cs proteins are sensitive to phosphatase treatment. 

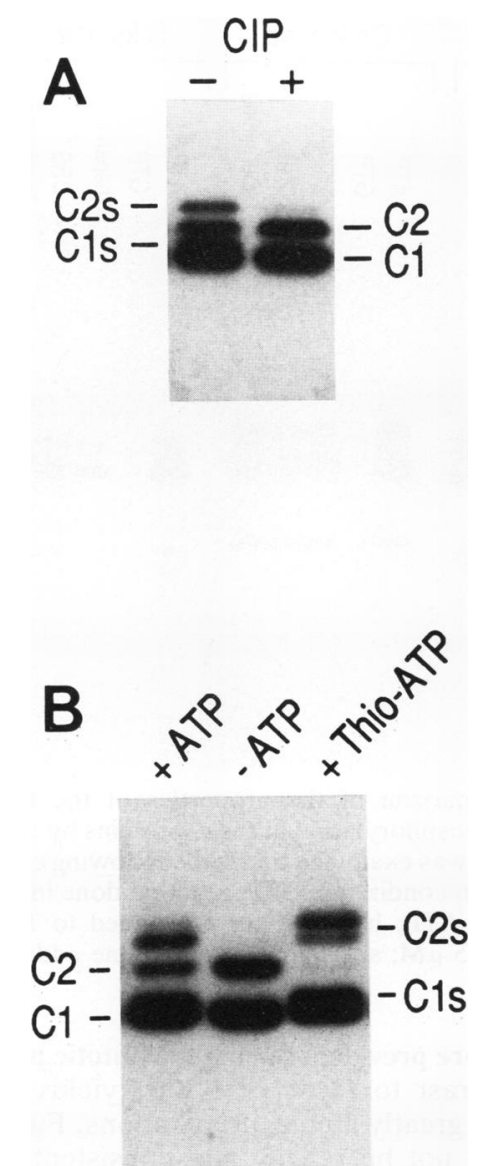

FIG. 2. Sensitivity of Cs proteins to alkaline phosphatase. (A) C and $\mathrm{Cs}$ proteins immunopurified with $4 \mathrm{~F} 4$ were digested with 0 (lane - CIP) or 2 (lane +CIP) U of CIP. At the end of the reaction, proteins were eluted from the beads, resolved by SDS-PAGE, and immunoblotted with monoclonal antibody 4F4. (B) Nuclear extract was incubated in the presence of ATP (lane +ATP) or [ $\gamma$-thio]ATP (lane + Thio-ATP) as described in the text. $\mathrm{C}$ and $\mathrm{Cs}$ proteins were then resolved by SDS-PAGE and detected by immunoblotting with 4F4. Lane - ATP, nuclear extract incubated without added ATP and creatine phosphate.

Cs proteins were immunopurified from nuclear extracts that had been preincubated with ATP, and the isolated Cs proteins were then treated with CIP and analyzed by SDSPAGE and immunoblotting with 4F4. As shown in Fig. 2A, incubation of Cs proteins with CIP resulted in reversal of the modification and conversion of $\mathrm{C} 1 \mathrm{~s}$ and $\mathrm{C} 2 \mathrm{~s}$ to $\mathrm{Cl}$ and $\mathrm{C2}$, as judged by the disappearance of the modified forms and a corresponding increase in the relative amounts of $\mathrm{C} 1$ and $\mathrm{C} 2$ (Fig. 2A, lane +). In contrast, no such change was observed when CIP was omitted (lane -). To verify that the modification is a phosphorylation, we compared the accumulation of Cs proteins in nuclear extracts incubated with [ $\gamma$-thio] ATP or native ATP. Whereas [ $\gamma$-thio]ATP is usually a substrate for protein kinases, the resulting modified proteins are less susceptible to phosphatase activity than their phosphorylated counterparts. Substitution of [ $\gamma$-thio]ATP for native ATP resulted in an even greater accumulation of $C$ proteins than that observed with native ATP (compare lane +ATP with lane + Thio-ATP in Fig. 2B). This is consistent with lower sensitivity of thio-Cs proteins to phosphatases

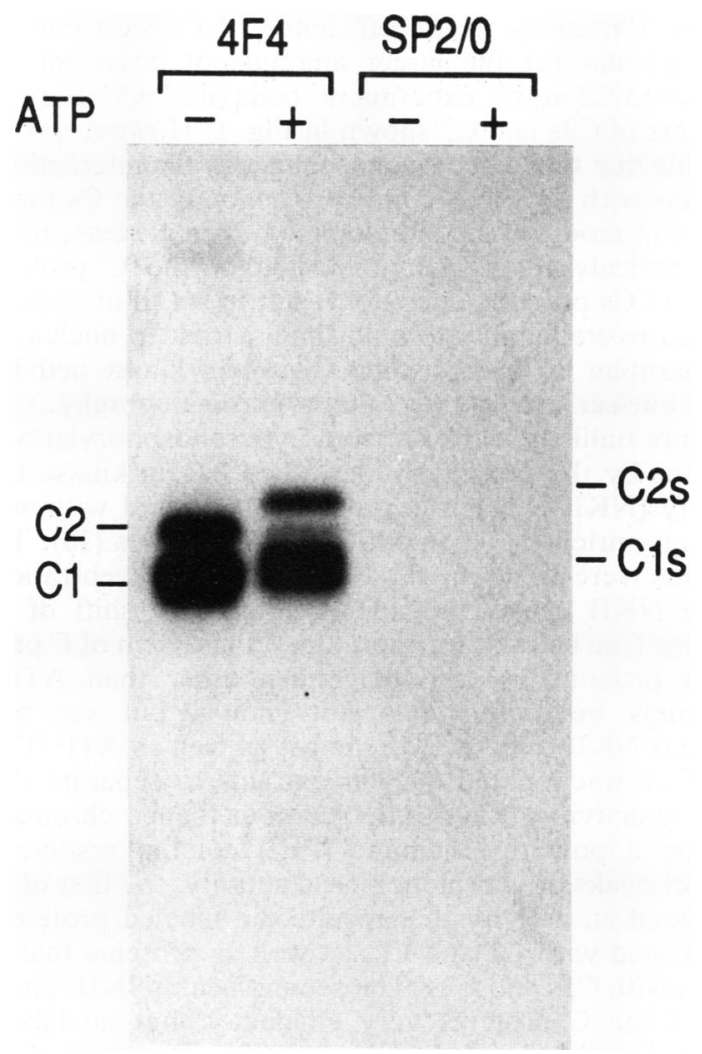

FIG. 3. UV light-induced cross-linking of C proteins to RNA in vitro. Nuclear extract was incubated with continuously labeled RNA following preincubation of the extract with (lane + ATP) or without (lane -ATP) ATP and creatine phosphate. After binding of nuclear extract proteins to the RNA, the reactions mixtures were UV irradiated for $10 \mathrm{~min}$ and digested with nucleases. Aliquots of each reaction mixture were immunopurified with $4 \mathrm{~F} 4$ or SP2/0 as indicated, and the proteins were resolved by SDS-PAGE. Crosslinking of $C$ proteins to the RNA was detected by label transfer from the RNA and visualized by autoradiography.

present in the extract. Taken together, these results show that C1s and C2s are phosphorylated forms of $\mathrm{C} 1$ and $\mathrm{C} 2$.

Cs proteins bind RNA in vitro. The possible effect of the modification of $C$ proteins to $C s$ proteins on their RNAbinding ability was tested by UV light-induced cross-linking of nuclear extract proteins to RNA. Irradiation with UV light results in covalent association of RNA with proteins in direct contact with it. If the RNA substrate is uniformly labeled, the cross-linked proteins can be identified by autoradiography, by virtue of residual labeled nucleotides which remain covalently attached to the protein and survive the nuclease digestion (see reference 29). As shown in Fig. 3, both $\mathrm{C}$ and Cs proteins became labeled upon exposure of the extracts to UV light, indicating that both forms of $\mathrm{C}$ proteins contact directly, and therefore most likely bind, the RNA in vitro (Fig. 3, lanes 4F4). The observed signal was consistently lower in extracts incubated in the presence of ATP than in extracts in which ATP was omitted (compare lanes 4F4+ and 4F4-), although independent experiments did not reveal detectable differences in the binding of $\mathrm{C}$ and $\mathrm{Cs}$ proteins to a variety of single-stranded nucleic acids, including singlestranded DNA and immobilized ribohomopolymers (data not shown). No labeled protein was immunopurified with immunoglobulins derived from parental myeloma line SP2/0 (lanes 
SP2/0). Variations in the efficiency of C-to-Cs conversion may account for the larger amounts of cross-linked C2s relative to $\mathrm{C} 2$ in this experiment, compared with the relative amounts of $\mathrm{C} 2 \mathrm{~s}$ and $\mathrm{C} 2$ shown in Fig. 1. However, it is also possible that this reflects some change in the interaction of $\mathrm{C}$ proteins with the RNA upon conversion to the Cs form that results in modified cross-linkability. Nonetheless, these results indicate that phosphorylation of the $\mathrm{C}$ proteins to generate Cs proteins does not result in an all-or-none effect on their overall ability to bind single-stranded nucleic acids.

Separation of three distinct $\mathbf{C}$ protein kinase activities in HeLa nuclear extracts by column chromatography. Cs proteins are unlikely to result from hyperphosphorylation of $\mathrm{C}$ proteins by the previously described casein kinase type II activity (NKII), which is partially associated with sucrose gradient-enriched $30 \mathrm{~S}$ to $40 \mathrm{~S}$ hnRNP particles (18). The Cs proteins were apparent even at low ATP concentrations, at which NKII caused no apparent mobility shift of the C proteins (see below). Furthermore, conversion of $\mathrm{C}$ proteins to Cs proteins by ribonucleotides other than ATP was extremely inefficient (data not shown, but see below), whereas NKII utilizes GTP almost as well as ATP (17). We therefore fractionated nuclear extracts to separate the Csforming activity from NKII. Anion-exchange chromatography on a polyethyleneimine (PEI) column resolved two distinct peaks of $C$ protein kinase activity, the first of which contained an activity that resulted in labeled proteins that comigrated with $\mathrm{C} 1$ and $\mathrm{C} 2$, as well as proteins that comigrated with $\mathrm{C} 1 \mathrm{~s}$ and $\mathrm{C} 2 \mathrm{~s}$. The second peak (NKII) phosphorylated the $\mathrm{C}$ proteins very efficiently, but no label was detected in the region of C1s and C2s. The peak of casein kinase type II activity, assayed by phosphorylation of exogenous casein in the presence of GTP instead of ATP, coeluted with this second peak (data not shown). Fractionation of the first peak from the PEI column by cationexchange chromatography on a sulfopropyl (SP-5PW) column resolved two distinct peaks of $C$ protein kinase activity, of which one resulted in almost exclusive labeling of Cs proteins (Cs kinase) while the other resulted in exclusive labeling of $\mathrm{C} 1$ and $\mathrm{C} 2$ (S kinase). Thus, at least three chromatographically distinct $\mathrm{C}$ protein kinase activities are present in HeLa cells.

The three peaks of kinase activity were distinguished from one another by their utilization of ATP and GTP, as well as by their different sensitivities to a variety of agents, as shown in Fig. 4. By these criteria, one of the activities corresponds to the previously identified NKII (lanes NKII), since it utilizes GTP almost as efficiently as ATP, is inhibited by a low concentration $(10 \mu \mathrm{g} / \mathrm{ml})$ of heparin, and is stimulated by spermidine $(17,18)$. The other two activities, Cs kinase and $S$ kinase, are cyclic AMP and calcium independent, are unaffected by cyclic AMP-dependent kinase inhibitor peptide PKI (6; data not shown), and cannot use GTP efficiently as a phosphate donor. The effect of the nucleotide analog DRB, a reported inhibitor of casein kinases type II (45), on the NKII peak was very variable in our experiments for unknown reasons. Thus, all three kinase activities are distinct from one another in chromatographic behavior as well as in sensitivity to the reagents described above. Phosphoamino acid analysis showed that all three kinases use predominantly serine residues on the $\mathrm{C}$ proteins as the phosphate acceptor amino acid (data not shown). We detected no endogenous $C$ protein kinase activity in the partially purified $\mathrm{C}$ protein preparation used, indicating that $\mathbf{C}$ proteins do not autophosphorylate under these conditions (data not shown).

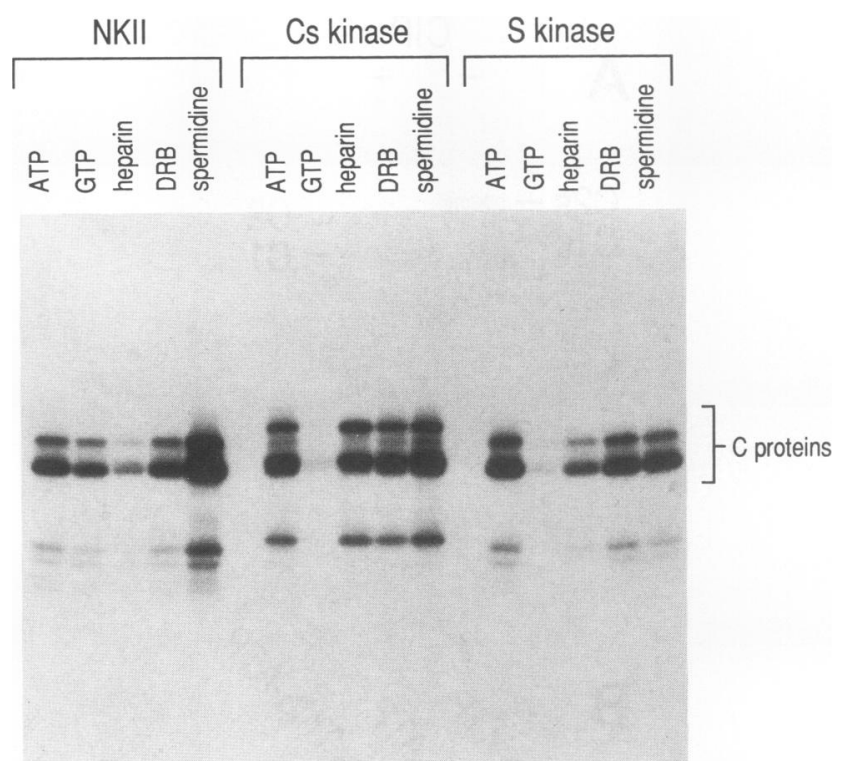

FIG. 4. Comparison of the properties of the three $\mathrm{C}$ protein kinase peaks. Phosphorylation of the $C$ proteins by each of the three kinase activities was examined under the following conditions: ATP, standard reaction conditions; GTP, reaction done in the presence of GTP instead of ATP; heparin, heparin added to $10 \mu \mathrm{g} / \mathrm{ml}$; DRB, DRB added to $75 \mu \mathrm{M}$; spermidine, spermidine added to $1 \mathrm{mM}$.

Cs proteins are prevalent during the mitotic phase of the cell cycle. In contrast to those of NKII, yields of Cs kinase activity varied greatly among preparations. Furthermore, Cs proteins could not be readily and consistently detected in lysates obtained from HeLa cells in different experiments, even in the presence of a variety of phosphatase inhibitors. While phosphatase activity was still a possible reason for the low levels of detectable Cs proteins, it was also possible that Cs proteins were nevertheless a very minor fraction of the total $\mathrm{C}$ proteins present in living cells at any given time. Alternatively, this also raised the possibility that the state of the cells used in different experiments, such as the proportion of cells at different stages of the cell cycle, determined the level of Cs proteins observed. We therefore examined whether Cs proteins were present at different levels in mitotic cells, compared with a randomly dividing, asynchronous cell population. Mitotic HeLa cells, obtained by selective mitotic detachment from cells grown in a monolayer, were directly lysed in SDS-PAGE sample buffer, and C proteins were detected by immunoblotting with monoclonal antibody 4F4. As shown in Fig. 5, most of the $\mathrm{C} 2$ protein was the $\mathrm{Cs}$ form in the mitotic sample. Immunopurification experiments indicated that an equivalent amount of $\mathrm{Cls}$, which was not resolved in immunoblots of total cell proteins, was also present in these samples (data not shown, but see Fig. 6). This is in contrast to the asynchronous cells, in which barely any Cs proteins were detectable. Time course experiments with synchronized cells also showed that Cs proteins are specifically enriched in mitosis (data not shown). Taken together with the results described thus far, these data indicate that the $\mathrm{C}$ proteins also undergo mitosisspecific phosphorylation. Additional evidence that the Cs proteins detected in mitotic cells are phosphorylated forms of the $\mathrm{C}$ proteins is provided by the facts that they were sensitive to phosphatase treatment (data not shown) and that they were extensively labeled in vivo with ${ }^{32} \mathbf{P}_{\mathbf{i}}$ (see below). 


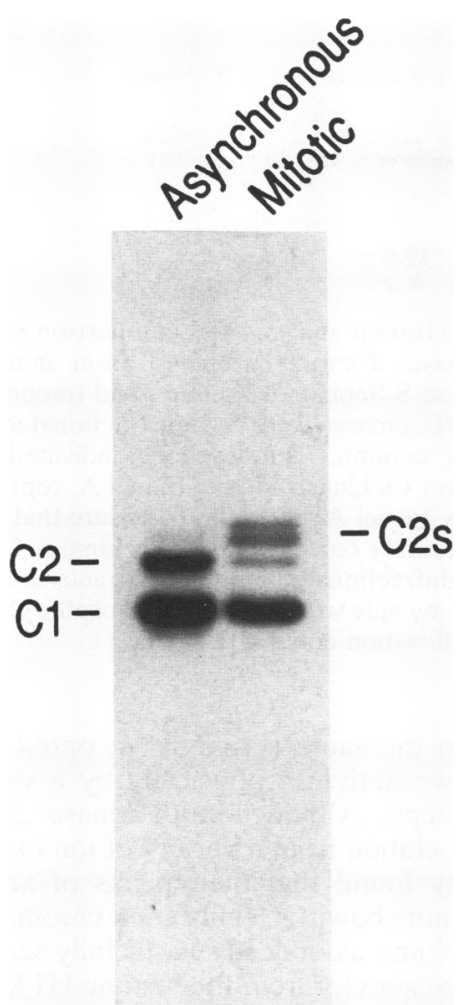

FIG. 5. Cs proteins are prevalent in the mitotic phase of the cell cycle. Mitotic HeLa cells were isolated by selective mitotic detachment as described in Materials and Methods. The cells were immediately lysed in SDS-containing sample buffer and boiled, and the proteins were resolved by SDS-PAGE (lane Mitotic). Whole-cell lysates were similarly prepared from asynchronously growing $\mathrm{HeLa}$ cells (lane Asynchronous). C and Cs proteins were detected by immunoblotting with 4F4.

Phosphorylation of hnRNPs during mitosis. Previous studies had shown that hnRNPs in the A and B groups (22), as well as additional hnRNPs (31), are extensively modified during mitosis, although the nature of these modifications was not known. To explore the extent to which hnRNPs other than $\mathbf{C}$ proteins are phosphorylated during the $\mathbf{M}$ phase, we immunopurified hnRNP complexes from M-phase HeLa cells which had been labeled with ${ }^{32} P_{i}$ and compared them with hnRNP complexes from similarly labeled asynchronous cells. The hnRNPs were subsequently resolved by two-dimensional gel electrophoresis, proteins were visualized with silver staining, and phosphorylated proteins were then detected by autoradiography. As Fig. 6 shows, C proteins, as well as hnRNPs $U$ and $G$, were the major phosphoproteins in interphase and mitotic hnRNP complexes. They also remained among the major substrates for phosphorylation in the $\mathrm{M}$ phase, although the mobility of the labeled $C$ proteins, as indicated by the results described above, was altered with respect to the phosphorylated interphase counterparts. Additional phosphorylated hnRNPs were detected in mitotic hnRNP complexes, in particular among those in the A and B groups. The labeled proteins coincided with the major silver-stained species detected in the mitotic hnRNP complexes, and their mobility was altered compared with that of their interphase counterparts $(22,31)$.

Cs kinase activity is enriched in mitotic cells. It was of interest to determine whether mitosis-specific phosphoryla-

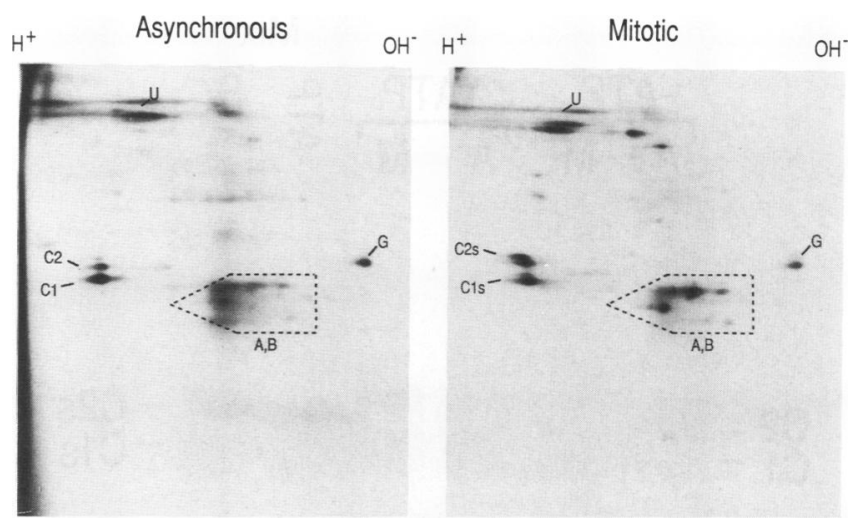

FIG. 6. Phosphorylation of hnRNPs in vivo in asynchronous and mitotic HeLa cells. hnRNP complexes were immunopurified from asynchronous or mitotic HeLa cells which had been labeled with ${ }^{32} \mathrm{P}_{\mathrm{i}}$ as described in the text. The proteins of the immunopurified complexes were resolved by two-dimensional gel electrophoresis, and phosphorylated proteins were visualized by autoradiography. The major phosphorylated hnRNPs are indicated.

tion of $\mathrm{C}$ proteins is merely a result of their exposure to a cytoplasmic activity to which they are not normally exposed in interphase cells, because of their nuclear restriction, or whether the changes in levels of Cs proteins actually reflect parallel changes in Cs kinase activity. We tested whole HeLa cell sonicates prepared from mitotic or interphase cells for Cs kinase activity in the presence of a vast excess of exogenous, partially purified $C$ proteins. Under these conditions, the contribution of endogenous $C$ proteins in the lysates to the signal observed by immunoblotting with 4F4 was negligible. In addition, use of whole-cell extracts ensured that any differences between the two populations of cells would not merely be the result of a redistribution of kinase activity between subcellular fractions. The same total protein concentration was used in both extracts to allow direct comparison of Cs kinase activity. As shown in Fig. 7, a mitotic-cell lysate altered the mobility of $\mathrm{C}$ proteins to a much greater extent than did a lysate prepared from asynchronous cells (compare + ATP lanes A and M), indicating that Cs kinase activity itself is enriched in mitosis. Immunoblotting, rather than phosphate transfer from $\left[\gamma-{ }^{32} \mathrm{P}\right] \mathrm{ATP}$, was used as the method of analysis in order to distinguish Cs kinase activity from activities of the other $\mathrm{C}$ protein kinases. The fact that a lower level of activity was observed in asynchronously dividing cells than in mitotic cells is unlikely to be due to the presence of a negative modulator of the kinase or to enriched phosphatase activity in nonmitotic cells, since mixing of the two extracts in the reaction did not reduce the Cs kinase activity contributed by the mitotic lysate (lanes Mix). Thus, it appears that the enrichment of Cs proteins in mitosis reflects a cell cycle-dependent regulation of Cs kinase activity.

Cs kinase phosphorylates $\mathrm{C}$ proteins in vitro at the major sites phosphorylated in vivo during mitosis, as judged by two-dimensional phosphopeptide maps of C2s protein (Fig. 8). The fact that additional peptides that were observed in the M-phase sample were absent from the Cs kinase sample may have resulted from phosphorylation by NKII or S kinase in addition to Cs kinase in mitosis, or it may have resulted from the action of additional kinases during mitosis. Furthermore, comparison with $\mathrm{C} 2$ protein isolated from labeled asynchronous cells demonstrated that $\mathrm{C} 2$ is phospho- 


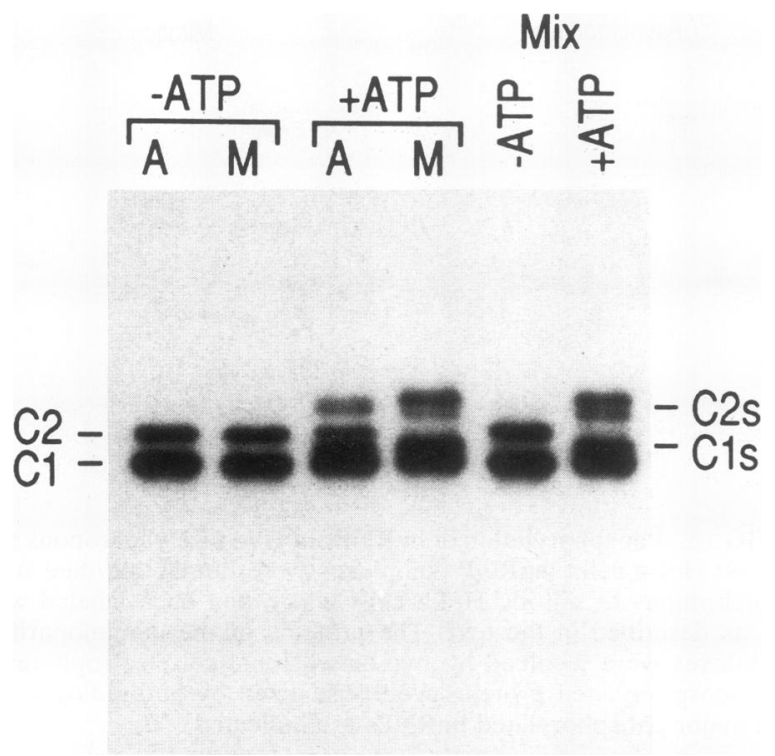

FIG. 7. Comparison of Cs kinase activities in asynchronous and mitotic cell extracts. Whole-cell extracts were prepared from asynchronously dividing cell cultures (lanes A) or from mitotic cells (lanes M) as described in the text. After normalization of the protein concentration of the extracts, they were incubated with a large excess of partially purified C proteins in the absence (lanes - ATP) or presence (lanes +ATP) of added ATP and creatine phosphate. Lanes Mix, reactions carried out in the presence of equal amounts of asynchronous and mitotic cell extracts in the absence (lane - ATP) or presence (lane +ATP) of ATP.

rylated at different sites during mitosis versus the interphase. Similar results were obtained with $\mathrm{C} 1$ (data not shown).

Cs kinase is distinct from histone H1 kinase. One of the best-characterized mitosis-specific kinases is the growth-associated histone H1 kinase, which has been shown to be a component of the mitotic inducer known as maturationpromoting factor (1; for reviews, see references 23 and 28$)$. It was therefore of interest to determine whether the Cs kinase

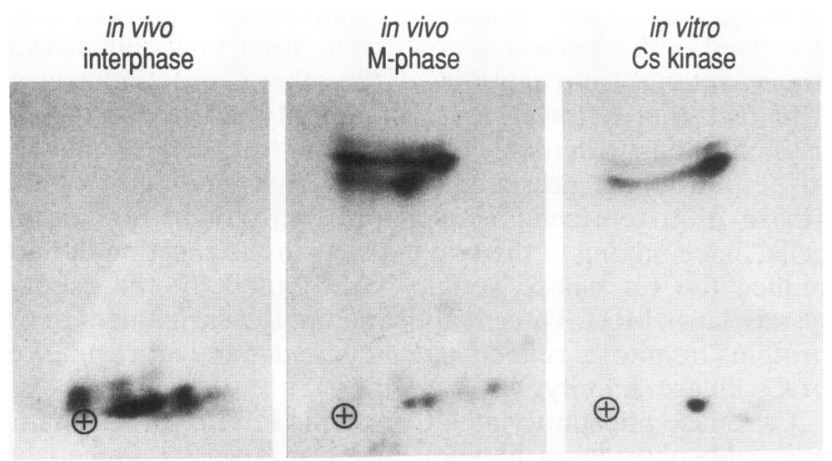

FIG. 8. Two-dimensional tryptic phosphopeptide maps of $\mathrm{C} 2$ protein. Phosphorylated C2 protein was isolated from interphase or mitotic HeLa cells labeled in vivo with ${ }^{32} \mathrm{P}_{\mathrm{i}}$ and from in vitro reactions with a Cs kinase-containing fraction that was devoid of detectable NKII or S kinase. The labeled, isolated proteins were digested with trypsin, and the resulting peptides were subjected to two-dimensional phosphopeptide mapping, with electrophoresis in the first dimension and ascending chromatography in the second dimension. The circled cross indicates the point of sample application.
A

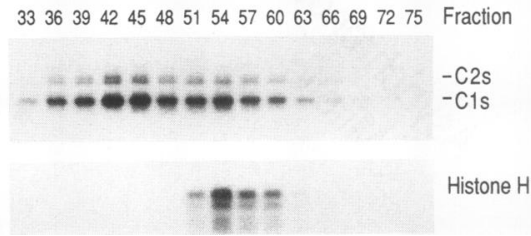

FIG. 9. Gel filtration analysis and comparison of Cs kinase and histone H1 kinase. Extracts prepared from mitotic cells were fractionated on an S-Sepharose column, and fractions enriched for $\mathrm{Cs}$ and histone $\mathrm{H} 1$ kinases were further fractionated on a Superose 12 gel filtration column. The fractions indicated were assayed simultaneously for Cs kinase activity (panel A, top) and histone $\mathrm{H} 1$ $\mathrm{C}$ kinase activity (panel A, bottom). To ensure that the observed $\mathrm{C}$ protein kinase activity corresponds to Cs kinase, $C$ proteins phosphorylated by unfractionated nuclear extracts were resolved by SDS-PAGE side by side with $C$ proteins phosphorylated by fraction 42 from the gel filtration column (B).

corresponds to the same activity. We opted to attempt to separate the two activities physically by a variety of chromatographic steps. Although both kinase activities overlapped in their elution from a variety of ion-exchange resins, we consistently found that their peaks of activity did not coincide (data not shown). Gel filtration chromatography on a Superose 12 column did indeed successfully separate the bulk of the Cs kinase activity from the histone $\mathrm{H} 1$ kinase activity. For this experiment, whole mitotic cell extracts were fractionated by chromatography on S-Sepharose as described in Materials and Methods. Fractions eluted from the column which contained both $\mathrm{Cs}$ kinase and histone $\mathrm{H} 1$ kinase activities were subsequently applied to a Superose 12 gel filtration column for further fractionation. The collected fractions were then assayed for the ability to phosphorylate $\mathrm{C}$ proteins and histone $\mathrm{H} 1$. As shown in Fig. 9, histone $\mathrm{H} 1$ kinase activity eluted as a more or less discrete peak at fraction 54. In contrast, Cs kinase activity eluted as a much broader peak, but the maximum activity was detected in fractions 42 to 45 , which were devoid of any detectable histone $\mathrm{H} 1$ kinase activity. The identity of the activity that phosphorylates $\mathrm{C}$ proteins as Cs kinase was confirmed by comparing $C$ proteins phosphorylated by fraction 42 with $C$ proteins phosphorylated in a crude nuclear extract. As can be seen in Fig. 9B, only the Cs proteins were labeled upon incubation of $C$ proteins with fraction 42 in the presence of $\left[\gamma-{ }^{32} \mathrm{P}\right] \mathrm{ATP}$. The pattern of phosphorylation of $\mathrm{C}$ proteins by the various fractions was unaffected by the presence of PKI (data not shown).

\section{DISCUSSION}

We have identified and characterized novel phosphorylated forms of the hnRNP C proteins, the Cs proteins. Cs proteins are distinct from previously described phosphorylated forms of the $C$ proteins in at least two aspects: the mobility of Cs proteins (but not of other phosphorylated forms of $\mathrm{C}$ proteins) on SDS-PAGE is retarded relative to that of $\mathrm{C}$ proteins, and the relative abundance of $\mathrm{Cs}$ proteins in vivo changes dramatically during the cell cycle, as they are most prevalent during mitosis. Of the three kinases which phosphorylate the C proteins, only one, Cs kinase, causes the alteration in electrophoretic mobility characteristic of Cs proteins. A second kinase has properties consistent with those of the NKII activity previously reported by 
Holcomb and Friedman (18). Further evidence that the Cs kinase is responsible for phosphorylation of $\mathrm{C}$ proteins to the Cs form in vivo during mitosis is provided by the fact that phosphopeptide maps of mitotic $\mathrm{C}$ proteins phosphorylated in vivo are similar to those of $C$ proteins phosphorylated in vitro by Cs kinase. Cs kinase activity appears to be distinct from p34 $4^{\mathrm{cdc} 2}$ and from other members of the family of cell cycle-regulated protein kinases that can use histone $\mathrm{H} 1$ as a substrate (see references 23 and 28), as it does not cofractionate with histone $\mathrm{H} 1$ kinase activity and cannot be efficiently immunoadsorbed with anti-p34 ${ }^{\text {cdc2 }}$ antibodies (data not shown). However, it is still possible that additional kinases also phosphorylate $\mathrm{C}$ proteins in mitosis.

The function of the phosphorylations of the $\mathrm{C}$ proteins both during the interphase and in mitosis is unknown. Phosphorylation has been widely implicated in the regulation of a large number of cellular processes. In other nuclear proteins, such as transcription factors, phosphorylation has been shown to regulate, among other factors, their intracellular localization, DNA-binding activity, and transcriptional activation (for reviews, see references 19 and 36). In contrast, very little is known about phosphorylation of RNA-binding proteins and the role of such modifications in posttranscriptional nuclear processes. A specific function for C proteins in RNA metabolism has not been clearly delineated, although several lines of evidence point to a central role for these proteins in RNA processing (see reference 15 and references therein). The function of the $\mathrm{C}$ proteins in such processes may be exerted either directly as a consequence of their binding to the RNA or by virtue of their interaction with other factors important in pre-mRNA processing. Both types of interactions could potentially be modulated by phosphorylation by the different kinases described here. While our experiments did not detect a direct effect of phosphorylation of the $\mathrm{C}$ proteins on their general single-stranded nucleic acid-binding properties, it is possible that these assays are not sufficiently sensitive to detect more subtle or specific changes.

Phosphorylation of the $\mathrm{C}$ proteins in mitosis to generate Cs proteins is of particular interest, as it correlates with drastic rearrangements in nuclear structure, as well as in RNA metabolism, that take place during this phase of the cell cycle (see reference 26). During mitosis, transcription by RNA polymerase II (and probably also pre-mRNA-processing events) is repressed $(34,40)$. The fate of pre-existing hnRNAs within these complexes is not known. (Are they spliced? Do they return to the nucleus after mitosis or degrade?) The overall structure of hnRNP complexes, however, appears to remain similar to that of interphase hnRNP complexes $(21,22,31)$. In addition to the $C$ proteins, other hnRNPs have also been shown to be modified during mitosis $(22,31)$, and our in vivo labeling results show that at least some of these modifications also result from phosphorylation. Phosphorylation of hnRNPs may serve to maintain the hnRNP proteins in complexes and prevent the breakdown of pre-existing hnRNAs. This may be important if the hnRNAs were required during or after mitosis, and it would also prevent precipitation of hnRNPs that would most likely occur if the RNAs to which they bind were depleted. With the breakdown of the nuclear envelope in mitosis, hnRNP proteins and hnRNP complexes that are otherwise confined to the nucleus during the interphase become exposed to the cytoplasm, which includes other RNA-containing complexes with which hnRNPs can potentially interact. Specific modifications of hnRNPs may serve to prevent such potentially deleterious interactions. It is noteworthy that most of the $C$ proteins detectable by total protein staining in mitotic cells are in the phosphorylated Cs form. The situation is similar for other mitosis-enriched phosphorylations, such as those of the A and B groups of proteins (Fig. 6; see also references 22 and 31).

Specific phosphorylation of C proteins and other hnRNPs in mitosis, or their dephosphorylation at the end of mitosis, may also play a role in their return to the nucleus once mitosis is completed and the daughter cell nuclei are reformed, which is of particular importance for proper nuclear function once transcription by RNA polymerase II resumes. Roles for phosphorylation or dephosphorylation in the regulation of nuclear protein import have been described for several proteins, particularly for transcription factors (see reference 20 and references therein; for reviews, see references 19 and 36). We showed previously that hnRNP complexes disassemble following mitosis and that hnRNPs localize to the nucleus separately by two modes of transport (31). The specific mechanism for dissociation of the hnRNP complex involved in this process is not known, but this rearrangement of hnRNP components may be analogous to the changes in composition that occur upon nucleocytoplasmic transport of mRNA during the interphase. Recent findings on the shuttling of hnRNPs between the nucleus and cytoplasm have raised the possibility that the shuttling hnRNPs (e.g., A1) accompany the mRNA through the nuclear pore during its transport to the cytoplasm, while the nucleus-restricted hnRNPs (e.g., C proteins) are probably selectively released from the mRNA-hnRNP complex prior to this transport process $(32,33)$. This disassembly of the hnRNP complex upon nucleocytoplasmic transport of mRNA may involve mechanisms similar to those in operation in the postmitotic disassembly of hnRNP complexes, and phosphorylation of hnRNPs may mediate such events.

While much work on mitosis-specific phosphorylation of proteins has focused on chromatin-associated proteins and structural components of the nucleus, as well as on transcriptional factors, little is known about the phosphorylation of nuclear proteins involved in posttranscriptional processes. Delineation of the specific sites on the $C$ proteins that are phosphorylated by Cs kinase, determining the function of the Cs modification, as well as further purification and characterization of Cs kinase (e.g., what other substrates, if any, it phosphorylates and what regulates its activity) should provide significant insights into both the cellular physiology of hnRNP complexes and the factors that regulate mitotic events. What is learned from Cs kinase and from the study of hnRNP complexes during mitosis is also likely to shed light on the function of the phosphorylation of other RNA-binding proteins.

\section{ACKNOWLEDGMENTS}

We are grateful to members of our laboratory for helpful discussions and comments on the manuscript.

This work was supported by the Howard Hughes Medical Institute and by grants from the National Institutes of Health.

\section{REFERENCES}

1. Arion, D., L. Meijer, L. Brizuela, and D. Beach. 1988. cdc2 is a component of the M-phase-specific histone $\mathrm{H} 1$ kinase: evidence for identity with MPF. Cell 55:371-378.

2. Bandziulis, R. J., M. S. Swanson, and G. Dreyfuss. 1989. RNA-binding proteins as developmental regulators. Genes Dev. 3:431-437.

3. Beyer, A. L., M. E. Christensen, B. W. Walker, and W. M. LeStourgeon. 1977. Identification and characterization of the packaging proteins of core 40S hnRNP particles. Cell 11:127138.

4. Bostock, C. J., D. M. Prescott, and J. B. Kirkpatrick. 1971. An 
evaluation of the double thymidine block for synchronizing mammalian cells at the G1-S border. Exp. Cell Res. 68:163-168.

5. Burd, C. G., M. S. Swanson, M. Görlach, and G. Dreyfuss. 1989. Primary structures of the heterogeneous nuclear ribonucleoprotein $\mathrm{A} 2, \mathrm{~B} 1$, and $\mathrm{C} 2$ proteins: a diversity of RNA binding proteins is generated by small peptide inserts. Proc. Natl. Acad. Sci. USA 86:9788-9792.

6. Cheng, H. C., B. E. Kemp, R. B. Pearson, A. J. Smith, L. Misconi, S. M. Van Patten, and D. A. Walsh. 1986. A potent synthetic peptide inhibitor of the cAMP-dependent protein kinase. J. Biol. Chem. 261:989-992.

7. Choi, Y. D., and G. Dreyfuss. 1984. Isolation of the heterogeneous nuclear ribonucleoprotein complex (hnRNP): a unique supramolecular assembly. Proc. Natl. Acad. Sci. USA 81:74717475.

8. Choi, Y. D., and G. Dreyfuss. 1984. Monoclonal antibody characterization of the $\mathrm{C}$ proteins of heterogeneous nuclear ribonucleoprotein complexes in vertebrate cells. J. Cell Biol. 99:1997-2004.

9. Choi, Y. D., P. J. Grabowski, P. A. Sharp, and G. Dreyfuss. 1986. Heterogeneous nuclear ribonucleoproteins: role in RNA splicing. Science 231:1534-1539.

10. Cooper, J. A., B. M. Sefton, and T. Hunter. 1983. Detection and quantification of phosphotyrosine in proteins. Methods Enzymol. 99:387-402.

11. Dignam, J. D., R. M. Lebovitz, and R. G. Roeder. 1983. Accurate transcription initiation by RNA polymerase II in a soluble extract from isolated mammalian nuclei. Nucleic Acids Res. 11:1475-1489.

12. Dreyfuss, G. 1986. Structure and function of nuclear and cytoplasmic ribonucleoprotein particles. Annu. Rev. Cell Biol. 2:459-498.

13. Dreyfuss, G., S. A. Adam, and Y. D. Choi. 1984. Physical change in cytoplasmic messenger ribonucleoproteins in cells treated with inhibitors of mRNA transcription. Mol. Cell. Biol. 4:415-423.

14. Dreyfuss, G., Y. D. Choi, and S. A. Adam. 1984. Characterization of hnRNA-protein complexes in vivo with monoclonal antibodies. Mol. Cell. Biol. 4:1104-1114.

15. Dreyfuss, G., M. J. Matunis, S. Piñol-Roma, and C. G. Burd. 1993. hnRNP proteins and the biogenesis of mRNA. Annu. Rev. Biochem. 62:289-321.

16. Dreyfuss, G., M. S. Swanson, and S. Piñol-Roma. 1988. Heterogeneous nuclear ribonucleoprotein particles and the pathway of mRNA formation. Trends Biochem. Sci. 13:86-91.

17. Hathaway, G. M., and J. A. Traugh. 1982. Casein kinasesmultipotential protein kinases. Curr. Top. Cell. Regul. 21:101127.

18. Holcomb, E. R., and D. L. Friedman. 1984. Phosphorylation of the C-proteins of HeLa cell hnRNP particles. J. Biol. Chem. 259:31-40.

19. Jackson, S. P. 1992. Regulating transcription factor activity by phosphorylation. Trends Cell Biol. 2:104-108.

20. Jans, D. A., M. J. Ackermann, J. R. Bischoff, D. H. Beach, and R. Peters. 1991. p34 ${ }^{\text {cdc2 }}$-mediated phosphorylation at $T^{124}$ inhibits nuclear import of SV-40 T antigen proteins. J. Cell Biol. 115:1203-1212.

21. Lahiri, D. K., and J. O. Thomas. 1985. The fate of heterogeneous nuclear ribonucleoprotein complexes during mitosis. J. Biol. Chem. 260:598-603.

22. Leser, G. P., and T. E. Martin. 1987. Changes in heterogeneous nuclear RNP core polypeptide complements during the cell cycle. J. Cell Biol. 105:2083-2094.

23. Maller, J. L. 1991. Mitotic control. Curr. Opin. Cell Biol. 3:269-275.

24. Moore, C. L., J. Chen, and J. Whoriskey. 1988. Two proteins crosslinked to RNA containing the adenovirus L3 poly(A) site require the AAUAAA sequence for binding. EMBO J. 7:31593169.

25. Nakagawa, T. Y., M. S. Swanson, B. J. Wold, and G. Dreyfuss. 1986. Molecular cloning of cDNA for the nuclear ribonucleoprotein particle $\mathrm{C}$ proteins: a conserved gene family. Proc. Natl.
Acad. Sci. USA 83:2007-2011.

26. Newport, J. W., and D. J. Forbes. 1987. The nucleus: structure, function and dynamics. Annu. Rev. Biochem. 56:535-565.

27. O'Farrell, P. Z., H. M. Goodman, and P. H. O'Farrell. 1977. High resolution two-dimensional electrophoresis of basic as well as acidic proteins. Cell 12:1133-1142.

28. Pines, J., and T. Hunter. 1991. Cyclin-dependent kinases: a new cell cycle motif? Trends Cell Biol. 1:117-121.

29. Piñol-Roma, S., S. A. Adam, Y. D. Choi, and G. Dreyfuss. 1989. Ultraviolet-induced crosslinking of RNA to proteins in vivo. Methods Enzymol. 180:410-418.

30. Piñol-Roma, S., Y. D. Choi, M. J. Matunis, and G. Dreyfuss. 1988. Immunopurification of heterogeneous nuclear ribonucleoprotein particles reveals an assortment of RNA-binding proteins. Genes Dev. 2:215-227.

31. Piñol-Roma, S., and G. Dreyfuss. 1991. Transcription-dependent and transcription-independent nuclear transport of hnRNP proteins. Science 253:312-314.

32. Piñol-Roma, S., and G. Dreyfuss. 1992. Shuttling of pre-mRNA binding proteins between nucleus and cytoplasm. Nature (London) 355:730-732.

33. Piñol-Roma, S., and G. Dreyfuss. 1993. hnRNP proteins: localization and transport between the nucleus and the cytoplasm. Trends Cell Biol. 3:151-155.

34. Prescott, D. M., and M. A. Bender. 1962. Synthesis of RNA and protein during mitosis in mammalian tissue culture cells. Exp. Cell Res. 26:260-268.

35. Preugschat, F., and B. Wold. 1988. Isolation and characterization of a Xenopus laevis C protein cDNA: structure and expression of a heterogeneous nuclear ribonucleoprotein core protein. Proc. Natl. Acad. Sci. USA 85:9669-9673.

36. Schmitz, M. L., T. Henkel, and P. A. Baeuerle. 1991. Proteins controlling the nuclear uptake of NK-кB, Rel and dorsal. Trends Cell Biol. 1:130-137.

37. Swanson, M. S., and G. Dreyfuss. 1988. Classification and purification of proteins of heterogeneous nuclear ribonucleoprotein particles by RNA-binding specificities. Mol. Cell. Biol. 8:2237-2241.

38. Swanson, M. S., and G. Dreyfuss. 1988. RNA binding specificity of hnRNP proteins: a subset bind to the $3^{\prime}$ end of introns. EMBO J. 11:3519-3529.

39. Swanson, M. S., T. Y. Nakagawa, K. LeVan, and G. Dreyfuss. 1987. Primary structure of human nuclear ribonucleoprotein particle $\mathrm{C}$ proteins: conservation of sequence and domain structures in heterogeneous nuclear RNA, mRNA and prerRNA-binding proteins. Mol. Cell. Biol. 7:1731-1739.

40. Taylor, J. H. 1960. Nucleic acid synthesis in relation to the cell division cycle. Ann. N. Y. Acad. Sci. 90:409-421.

41. Tobey, R. A., E. C. Anderson, and D. G. Peterson. 1967. Properties of mitotic cells prepared by mechanically shaking monolayer cultures of Chinese hamster cells. J. Cell. Physiol. 70:63-68.

42. van Eekelen, C. A. G., and W. J. van Venrooij. 1981. hnRNA and its attachment to a nuclear protein matrix. J. Cell Biol. 88:554-563.

43. Wilk, H. E., H. Werr, D. Friedrich, H. H. Kiltz, and K. P. Schaefer. 1985. The core proteins of $35 \mathrm{~S}$ hnRNP complexes: characterization of nine different species. Eur. J. Biochem. 146:71-81.

44. Wilusz, J., D. I. Feig, and T. Shenk. 1988. The C proteins of heterogeneous nuclear ribonucleoprotein complexes interact with RNA sequences downstream of polyadenylation cleavage sites. Mol. Cell. Biol. 8:4477-4483.

45. Zandomeni, R., M. C. Zandomeni, D. Shugar, and R. Weinman. 1986. Casein kinase II is involved in the inhibition by 5,6dichloro-1- $\beta$-D-ribofuranosylbenzimidazole of specific RNA polymerase II transcription. J. Biol. Chem. 261:3414-3419.

46. Zieve, G. W., D. Turnbull, J. M. Mullins, and J. R. McIntosh. 1980. Production of large numbers of mitotic mammalian cells by the use of the reversible microtubule inhibitor nocodazole. Exp. Cell Res. 126:397-405. 